\title{
SECAGEM CONVECTIVA DE SEMENTES DE UVA: INFLUÊNCIA NO CONTEÚDO DE ÓLEO EXTRAÍDO
}

\author{
G. P. BRUNI ${ }^{1}$, F. M. OLIVEIRA ${ }^{1}$, V.T.CREXI ${ }^{1}$, G. S. ROSA ${ }^{2}$ e E.G. OLIVEIRA ${ }^{3}$ \\ ${ }^{1}$ Universidade Federal do Pampa, Curso de Engenharia de Alimentos \\ ${ }^{2}$ Universidade Federal do Pampa, Curso de Engenharia Química \\ ${ }^{3}$ Universidade Federal do Rio Grande do Sul, Departamento de Tecnologia de Alimentos \\ E-mail para contato: graziellabruni@yahoo.com.br
}

\begin{abstract}
RESUMO - A região da campanha do Rio Grande do Sul tem recebido destaque na produção de vinhos o que aumenta a geração de resíduos. As sementes de uva possuem óleo, um composto valioso devido ao rico conteúdo de ácidos graxos. As condições de estocagem e processamento das sementes oleaginosas afetam diretamente a qualidade dos seus produtos finais. Em face disso, o estudo da operação de secagem é essencial, pois a temperatura de secagem pode afetar as propriedades fisico-químicas do óleo, ocasionando a oxidação e alteração dos pigmentos presentes no óleo. A realização do trabalho teve o objetivo de avaliar o processo de secagem convectiva de sementes de uva, verificando a influência desta operação No conteúdo de óleo extraído. Os ensaios de secagem foram realizados em secador de leito fixo com escoamento paralelo de ar, nas temperaturas de 40,60 e $80^{\circ} \mathrm{C}$ e velocidade do ar de $2 \mathrm{~m} / \mathrm{s}$. Os resultados de cinética de secagem apresentaram período de taxa constante, seguido de período de taxa decrescente. Verificou-se através da análise estatística que as diferentes temperaturas de secagem das sementes não proporcionaram diferenças significativas no conteúdo de óleo extraído $(p>0,05)$.
\end{abstract}

\section{INTRODUÇÃO}

O Brasil é considerado um dos países que mais produzem resíduos agroindustriais, devido a intensa atividade agrícola (Cataneo et al.,2008). As agroindústrias de alimentos produzem anualmente grande quantidade de resíduos líquidos e sólidos. Estes resíduos são constituídos, principalmente, por material orgânico biodegradável, e sua deposição gera sérios problemas ambientais. Apesar de poder ser aproveitada como ração animal ou disposta no campo, a maior parte dos resíduos agroindustriais ainda é descartada sem tratamento, com alto potencial de impacto ao meio ambiente (Hang, 2004; Makris et al., 2007; Melo et al., 2011).

Segundo Cataneo et al. (2008) a utilização dessa matéria orgânica é um problema enfrentado pelas indústrias vinícolas, pois é longo o tempo que o resíduo vitivinícola leva para se decompor tornando-se assim fonte de poluente ambiental. 
De acordo com Mello (2008), a viticultura ocupa uns dos setores frutíferos mais importantes no Brasil, concentrada em diversas regiões, onde se destacam como maiores produtores nacional, os Estados das Regiões Sul, Sudeste e Nordeste. Na elaboração do vinho, o bagaço de uva é o principal subproduto e representa cerca de $20 \%$ do peso original das uvas

(Gomez-Plaza et al., 2006; Llobera e Cañellas, 2007; Ruberto et al., 2007). O bagaço de uva é formado, em média, por $58 \%$ de cascas, $20 \%$ de engaços e $22 \%$ de sementes (Dantas et al., 2008). A semente de uva é composta ainda, por aproximadamente $40 \%$ de fibras, 8 a $11 \%$ de proteínas, $7 \%$ de compostos fenólicos complexos (taninos), açúcares, sais minerais, etc. (Rockenbach, 2012).

O óleo presente nesta semente é rico em tocoferol (vitamina E - antioxidante), principalmente na forma alfa-tocoferol e também possui grandes quantidades de ácidos graxos, destacando-se alto teor de ácido linoleico, o qual é um ácido graxo essencial ao ser humano (Moretto e Fett, 1998). Além disso, estudos têm demonstrado que o óleo de semente de uva apresenta a propriedade de atuar contra a oxidação das lipoproteínas de baixa densidade, podendo ser utilizado também na prevenção da trombose e de doenças cardiovasculares, além de auxiliar na redução do colesterol, na dilatação dos vasos sanguíneos e na regulação do sistema nervoso autônomo (Campos, 2005).

A semente de uva possui teor de água de aproximadamente $42 \%$ em base úmida (Crexi et al., 2013), o que a torna altamente perecível. A secagem desse resíduo, em condições adequadas pode aumentar a vida útil e facilitar a etapa de extração de óleo que nela está contido (Garcia e Perez et al., 2010). Filho et al. (2013), observaram que a temperatura de secagem influenciou no conteúdo de óleo de semente de uva de subproduto vitivinícola, obtendo um conteúdo de $10 \%$ de óleo nas sementes secas e $12 \%$ nas sementes in natura.

O desenvolvimento do trabalho foi feito com o objetivo de avaliar o processo de secagem convectiva de sementes de uva nas temperaturas de 40,60 e $80{ }^{\circ} \mathrm{C}$, verificando a influência desta operação no conteúdo de óleo extraído.

\section{MATERIAIS E MÉTODOS}

\subsection{Obtenção da matéria-prima}

As amostras utilizadas para a realização do presente trabalho foram as sementes de uva da variedade Chardonnay obtidas de uma vinícola da região de Bagé - RS. A Figura 1 ilustra o fluxograma das etapas realizadas para obtenção das sementes de uva. 


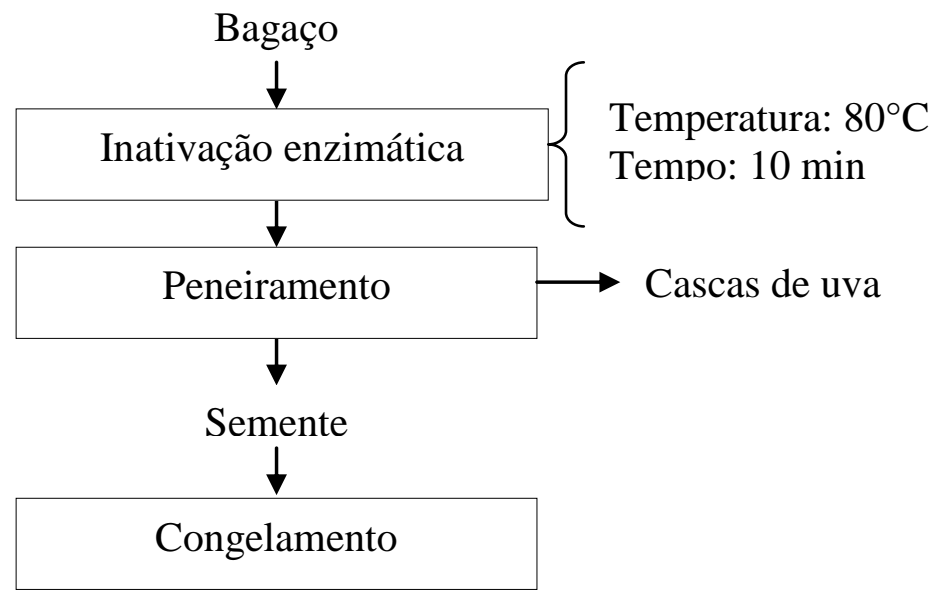

Figura 1 - Fluxograma das etapas realizadas para a obtenção das sementes de uva

Para inativação enzimática o bagaço de uva foi submetido a tratamento térmico em estufa com circulação de ar a $80^{\circ} \mathrm{C}$ por 10 min conforme descrito por Rockenbach (2010), esta foi realizada com intuito de preservar a amostra e evitar a oxidação enzimática do óleo presente na semente. Após, realizou-se a etapa de peneiramento do bagaço para a separação das sementes e por fim o armazenamento sob congelamento a $-18{ }^{\circ} \mathrm{C}$.

A Figura 2 ilustra a matéria-prima utilizada antes e após a etapa de preparo, respectivamente.
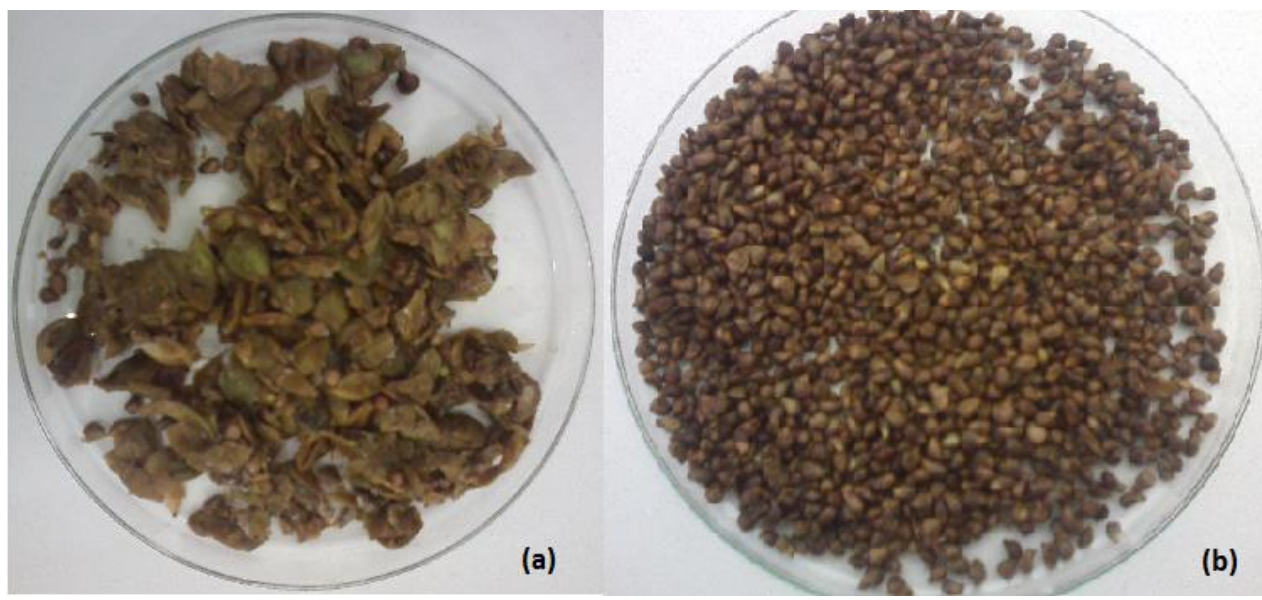

Figura 2 - (a) Bagaço (b) Semente de uva. 


\subsection{Equipamento e Metodologia Experimental}

Para realização da secagem utilizou-se um secador de túnel com escoamento paralelo de ar (Figura 3) nas temperaturas de 40,60 e $80{ }^{\circ} \mathrm{C}$, com velocidade do ar de secagem de $2 \mathrm{~m} / \mathrm{s}$, sendo essas condições pré- estabelecidas em testes preliminares.

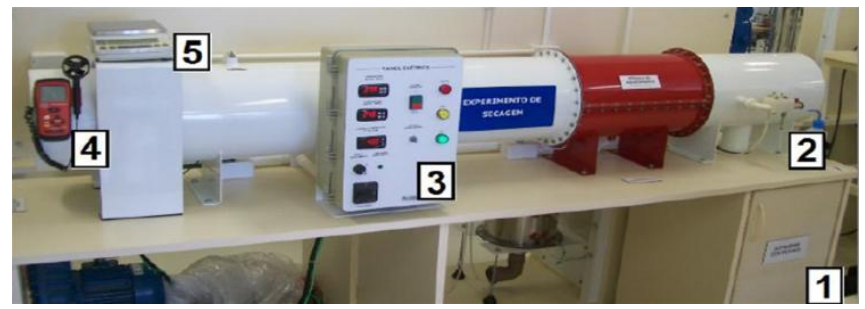

Figura 3 - Secador de leito fixo.

(1) Compartimento com o Soprador centrífugo; (2) Psicrômetro; (3) Painel elétrico; (4) Anemômetro; (5) Balança eletrônica.

Incialmente no ensaio de secagem, verificou-se se o psicrômetro estava preenchido com água. O soprador foi ligado, ajustando a velocidade do ar de secagem requerida. Após atingir as condições de regime permanente, a bandeja (espessura de $0,5 \mathrm{~cm}$ ) com $55 \mathrm{~g}$ de amostra foi inserida no interior do secador, registrando o peso inicial do conjunto. Foram monitoradas durante o experimento as condições massa da amostra, temperatura do bulbo seco e bulbo úmido com auxilio do psicrômetro, e a temperatura do ar de secagem, até massa constante, assim sendo finalizado o processo de secagem.

A determinação de umidade inicial e final da amostra foi realizada em triplicatas segundo a metodologia descrita pelo Instituto Adolfo Lutz (2008), através do método de estufa a 105 ${ }^{\circ} \mathrm{C}$ por $24 \mathrm{~h}$.

Após os ensaios de secagem o óleo presente nas sementes foi extraído através do método de Soxhlet utilizando-se hexano como solvente a uma temperatura na faixa de $68-70{ }^{\circ} \mathrm{C}$ durante 6 h de extração. Para a análise estatística dos resultados foi utilizado o teste de Tukey, a fim de verificar as diferenças significativas para o conteúdo de óleo extraído $(p \leq 0,05)$.

\section{RESULTADOS E DISCUSSÃO}

Na Tabela 1 são apresentado os valores de umidade (base úmida) da sementes de uva in natura e secas nas temperaturas de 40,60 e $80^{\circ} \mathrm{C}$. 
Tabela 1 - Valores de umidade em base úmida das sementes in natura e secas nas temperaturas de secagem de 40,60 e $80{ }^{\circ} \mathrm{C}$

\begin{tabular}{|c|c|c|c|}
\hline \multirow{2}{*}{ Umidade } & \multicolumn{3}{|c|}{ Temperatura de Secagem $\left({ }^{\circ} \mathrm{C}\right)$} \\
\hline & 40 & 60 & 80 \\
\hline in natura $\mathrm{g}_{\text {água }} / \mathrm{g}_{\text {amostra }}$ & $0,4367 \pm 0,0020$ & $0,4367 \pm 0,0020$ & $0,4271 \pm 0,0236$ \\
\hline in natura $\mathrm{g}_{\mathrm{a} g u a} / \mathrm{g}_{\mathrm{ss}}$ & $0,7752 \pm 0,0080$ & $0,7752 \pm 0,0080$ & $0,7482 \pm 0,0720$ \\
\hline secas gágua $/ g_{\text {amostra }}$ & $0,0847 \pm 0,0130$ & $0,0505 \pm 0,0120$ & $0,0364 \pm 0,0220$ \\
\hline secas gágua $/ g_{s s}$ & $0,0926 \pm 0,0130$ & $0,0532 \pm 0,0013$ & $0,0378 \pm 0,0021$ \\
\hline
\end{tabular}

Valores médios \pm desvio médio $(\mathrm{n}=2)$.

Crexi et al. (2013), que caracterizaram as sementes de uvas da variedade Cabernet Sauvignon encontraram valores de umidade semelhantes aos apresentados na Tabela 1 para a semente de uva in natura, sendo este de 42, $8 \%$ (b.u.).

As curvas de cinética de secagem das sementes secas em leito fixo foram construídas a partir do conteúdo de umidade (b.s) em função do tempo. Os resultados das curvas de secagem encontram-se na Figura 3, em que as temperaturas das secagens foram 40, 60 e $80{ }^{\circ} \mathrm{C}$ e velocidade do ar $2 \mathrm{~m} / \mathrm{s}$.

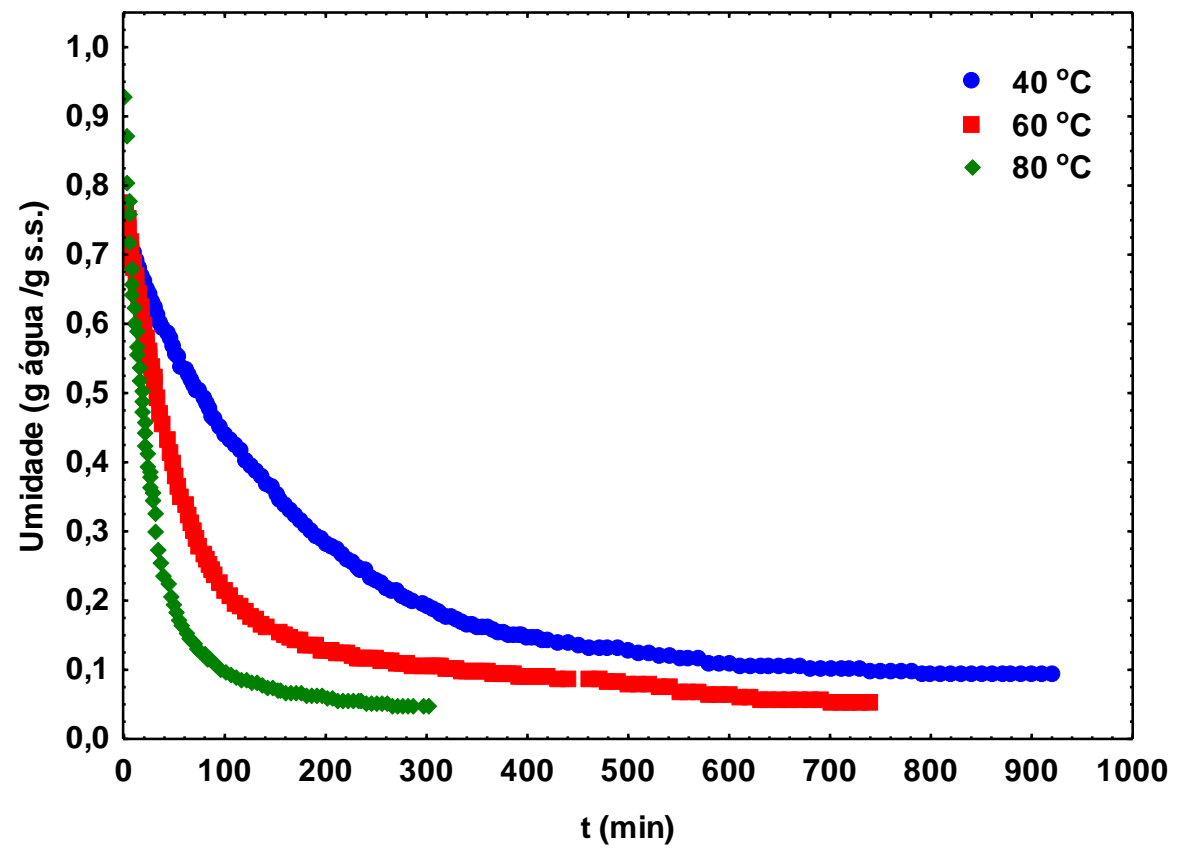

Figura 4 - Cinética de secagem para as diferentes condições de operação. 
Na Figura 4 pode-se verificar que com o aumento da temperatura do ar ocorreu aceleração do processo de secagem, proporcionando um tempo mais curto de processo. Ao final da secagem, a umidade atinge o equilíbrio e a massa do material não varia mais, pois atingiu o conteúdo de umidade de equilíbrio com a atmosfera correspondente.

Os resultados obtidos indicam que a secagem ocorreu inicialmente em um período de taxa constante, e após em período de taxa decrescente. Verifica-se também, que para um mesmo tempo, quanto maior a temperatura do ar, maior é a taxa de secagem e que a perda do conteúdo de umidade é mais rápida no início do processo de secagem. De acordo com Mujumdar (2006) durante o período de secagem em taxa decrescente, os fatores que influenciam o processo são função da natureza física do produto, a temperatura, e o seu teor de umidade. Neste período ocorre a retirada da umidade interna do material.

Na Tabela 2 são apresentados os teores de óleo obtidos após extração por Soxhlet em base úmida e seca para as diferentes amostras secas.

Tabela 2 - Conteúdo de óleo em base úmida e seca

\begin{tabular}{cccc}
\hline \multirow{2}{*}{ Conteúdo de Óleo } & \multicolumn{3}{c}{ Temperatura de Secagem $\left({ }^{\circ} \mathbf{C}\right)$} \\
\cline { 2 - 4 } & $\mathbf{4 0}$ & $\mathbf{6 0}$ & $\mathbf{8 0}$ \\
\hline Base úmida $\mathrm{g}_{\text {óleo }} / \mathrm{g}_{\mathrm{amostra}}$ & $0,1159 \pm 0,0031$ & $0,1151 \pm 0,0040$ & $0,1241 \pm 0,0004$ \\
Base seca $\mathrm{g}_{\text {oleo }} / \mathrm{g}_{\mathrm{ss}}$ & $0,1268 \pm 0,0033^{\mathrm{a}}$ & $0,1212 \pm 0,0042^{\mathrm{a}}$ & $0,1288 \pm 0,0005^{\mathrm{a}}$ \\
\hline
\end{tabular}

Valores médios \pm desvio médio $(n=2)$. Letras iguais na mesma linha $(p>0,05)$. Letras diferentes na mesma linha $(p<0,05)$.

$\mathrm{Na}$ extração de óleo, a secagem de grãos e frutos é uma prática usual que facilita o processo no que diz respeito ao contato entre o solvente e o soluto (óleo) a ser extraído, resultando em maiores rendimentos (Tango et al., 2004).

Segundo Menezes e Pereira (2013) a melhor temperatura de secagem de sementes de uva da variedade Bordô para a extração por prensagem foi de $40{ }^{\circ} \mathrm{C}$, onde o valor encontrado para o teor de óleo em base úmida foi de 10,31 \%. Já Kajihara et al.. (2013), para a mesma variedade de uva, encontraram 15 a $17 \%$ de óleo na extração por solvente, sendo a temperatura de secagem de $80{ }^{\circ} \mathrm{C}$ a mais adequada para obtenção do óleo.

Para o presente estudo, as amostras secas nas temperaturas de 40,60 e $80{ }^{\circ} \mathrm{C}$ apresentaram conteúdo de óleo extraído semelhantes, como pode ser observado na Tabela 2. Os resultados obtidos através da análise estatística utilizando o teste de Tukey, demonstraram que estes não diferiram estatisticamente entre si $(\alpha=95 \%)$. 


\section{CONSIDERAÇÕES FINAIS}

Os resultados obtidos demonstram que a temperatura do ar de secagem influencia no comportamento da secagem e que quanto maior a temperatura utilizada, mais rápido ocorre o processo. No início do processo de secagem, houve período de taxa constante, e posteriormente um período a taxa decrescente. Foi possível verificar também que mesmo empregando-se temperaturas de secagem diferentes, 40, 60 e $80{ }^{\circ} \mathrm{C}$, o conteúdo de óleo extraído não diferiu-se estatisticamente.

\section{REFERÊNCIAS}

CAMPOS, L. M. A. S.; MICHIELIN, E. M. Z.; DANIELSKI, L.; FERREIRA, S. R. S., Experimental data and modeling the supercritical fluid extraction of marigold (Calendulaof.cinalis) oleoresin. J. Supercrit. Fluids, v. 34, n. 2, p. 163-170, 2005.

CATANEO, C. B.; CALIARI, V.; GONZAGA, L. V.; KUSKOSKI, E. M.; FETT, R. Atividade

antioxidante e conteúdo fenólico do resíduo agroindustrial da produção de vinho. Semina: Ciências Agrárias, Londrina, v. 29, n. 1, p. 93-102, jan./mar. 2008

CREXI, V. T.; MORAIS, M. M.; BITTENCOURT, C. R.; BRUNI, G. P.; SANTOS, R. B. Caracterização química da semente de uva da variedade Cabernet Sauvigno. XXV Congresso Regional de Iniciação Científica e Tecnológica em Engenharia - cricte 2013.

DANTAS, F.R.; ARAÚJO, G.G.L. de; SILVA, D.S. da; PEREIRA, L.G.R.; GONZAGA NETO, S.; TOSTO, M. da S.L. Composição química e características fermentativas de silagens de maniçoba (Manihot sp.) com porcentuais de co-produto de vitivinícolas desidratado. Revista Brasileira de Saúde e Produção Animal, v.9, p.247-257, 2008.

FILHO, C. A. B.; OLIVEIRA, E.G.; TEIXEIRA, R. F.; BORTOLOTTO, M. S.; TERGOLINO, B. A. Influência da temperatura de secagem no rendimento de óleo de semente de uva separadas dos subprodutos da vinificação. V Salão Internacional De Ensino, Extensão e Pesquisa - SIEPE 2013.

FREITAS, L. S., Desenvolvimento de procedimentos de extração do óleo de semente de uva e caracterização química dos compostos extraídos. Tese (Doutorado), Universidade Federal do Rio Grande do Sul, 2007.

GARCIA-PEREZ, J.V.; GARCIA-ALVARADO, M.A.; CARCEL, J.A.; MULLET, A. Extraction kinetics modeling of antioxidants from grape stalk (Vitis vinifera var. Bobal): influence of drying conditions. Journal of Food Engineering, v.101, p.49-58, 2010. 
GOMEZ-PLAZA, E.; MIÑANO, A.; LOPEZ-ROCA, J.M. Comparison of chromatic properties, stability and antioxidant capacity of anthocyanin-based aqueous extracts from grape pomace obtained from different vinification methods. Food Chemistry, v.97, p.87-94, 2006.

HANG, Y.D. Management and utilization of food processing wastes. Journal of Food Science, v.69, p.104-107, 2004.

INSTITUTO ADOLFO LUTZ. Métodos químico e física para análises de alimentos, ed IV, $1^{\mathrm{a}}$ edição digital , p. 1020, São Paulo, 2008.

KAJIHARA, V. Y.; MENEZES, M.S.; SAKAMOTO, M. S. C.; PEREIRA, N. C. Extração de óleo de semente de uva da variedade Bordô por soxhlet. XI EPCC - Encontro Interrnacional de Produção Científica Cesumar UNICESUMAR - Centro Universitário Cesumar. Editora CESUMAR Maringá - Paraná - Brasil

LLOBERA, A.; CAÑELLAS, J. Dietary fibre content and antioxidant activity of Manto Negro red grape (Vitis vinifera): pomace and stem. Food Chemistry, v.101, p.659-666, 2007.

MAKRIS, D.P.; BOSKOU, G.; ANDRIKOPOULOS, N.K.Polyphenolic content and in vitro antioxidant characteristics of wine industry and other agri-food solid waste extracts. Journal of Food Composition and Analysis, v.20, p.125-132, 2007.

MELLO, L.M.R. Viticultura brasileira: panorama 2011. Bento Gonçalves: Embrapa Uva e Vinho, 2012. (Embrapa Uva e Vinho. Comunicado técnico, 115).

MORETTO, E.; FETT, R., Tecnologia de óleos e gorduras vegetais na indústria de alimentos, Ed. Varela, São Paulo, 1998.

MUJUMDAR, A. S. Handbook of industrial drying. 3 ed. Ed. CRC Press, Nova York, 2006.

ROCKENBACH, I. I., JUGFER, E., RITTER, C., SANTIAGO-SCHÜBEL, B., THIELE, B., FETT, R., GALENSA, R. (2012). Characterization of flavan-3-oils in seeds of grape pomace by CE, HPLC-DAD-DMS and LC-ESI-FTICR-MS. Food Research International. 48 , p. $848-855$.

RUBERTO, G.; RENDA, A.; DAQUINO, C.; AMICO, V.; SPATAFORA, C.; TRINGALI, C.; DE TOMMASI, N. Polyphenol constituents and antioxidant activity of grape pomace extracts from five sicilian red grape cultivars. Food Chemistry, v.100, p.203-210, 2007.

TANGO, J. S.; CARVALHO, C. R. L.; SOARES, N. B. Caracterização física e química de frutos de abacate visando a seu potencial para extração de óleo. Revista Brasileira de Fruticultura, v. 26, n. 1, p. 17-23, 2004. 